\title{
PRIMJENA 3D SKENERA U FUNKCIJI DIGITALNE ANTROPOMETRIJE STOPALA (FootSABA 3D Foot Scanner)
}

\author{
Sarajko Baksa1, Ines Baksa², Budimir Mijovićc \\ ${ }^{1}$ Međimursko veleučilište u Čakovcu, Čakovec \\ 2SABALab, Zagreb \\ ${ }^{3}$ Sveučilište u Zagrebu, Tekstilno - tehnološki fakultet, Zagreb
}

E-mail: sarajko_baksa@yahoo.com, ines_baksa@yahoo.com, budimir.mijovic@ttf.hr

Izvorni znanstveni rad

UDK: [572.087:611.986]:004.352.4(086.4)

\begin{abstract}
Sažetak
Personalizacija dimenzija i oblika obuće od iznimnog je značaja i u današnje vrijeme od strane interdisciplinarnih struka (medicinske, obućarske, ergonomske ...) priznata kao vitalno važna, glede toga jer pogrešno izvedena obuća neminovno rezultira s neželjenim patološkim stanjima stopala. Cilj ovog istraživanja bio je znanstveno utvrditi primjenu automatizirane 3D digitalizacije prostorne antropometrijske izmjere stopala u odnosu na učestalost pogrešno odabrane obuće na temelju tradicionalnih metoda izmjere i odabira. Među ispitanim entitetima, podjednako muškog i ženskog spola utvrđeno je da više od dvije trećine osoba nosi obuću koja ergonomski nije odgovarala temeljnim antropometrijskim izmjerama obuće, kako u širini, tako ni u duljini njihovih stopala. Postoje medicinski dokazi da je nošenje neodgovarajuće obuće usko povezano s bolovima i ranama u stopalima, a trajnim nošenjem i patološkim promjenama stopala, kao primjerice deformacijom stopala i nožnih prstiju. Tradicionalne metode determiniranja morfologije stopala u svom opsegu uzimanja mjera nisu dovoljne da točno definiraju oblik i veličinu, za razliku od suvremenog pristupa uporabe 3D skenera i digitalnih metoda izmjera 3D virtualnih modela, koji su u mogućnosti iznimno precizno i brzo personalizirati veliki broj antropometrijskih podataka morfologije stopala.
\end{abstract}

\section{Ključne riječi}

Stopalo, 3D virtualni model, 3D skener, antropometrijsko mjerenje

\section{Uvod}

Primjena 3D skenera u funkciji digitalne antropometrije stopala je potencijalno izgledna tehnologija budućnosti za ostvarenje potreba korisnika, u obliku individualiziranih proizvoda. Pristalost i udobnost obuće, jedan je od temeljnih antropometrijskih čimbenika korisnika. Modno dizajniranje i funkcionalno konstruiranje obuće je vrlo složen proces, glede potrebnog zadovoljavanja dijametralno suprotnih zahtjeva funkcionalnosti i estetike.

Obzirom na to da su bazni ulazni podaci antropometrijske izmjere stopala korisnika, unutar ovog rada predstavit će se znanstvena istraživanja $i$ analiza rezultata izmjera tradicionalnim ručnim metodama uzimanja mjera stopala korisnika u suodnosu prema recentnim metodama uzimanja mjera stopala korisnika metodama korištenja specijaliziranih 3D prostornih skenogramskih mjernih sustava.

Povijesno temeljna uloga obuće je zaštita, što je iznimno važan dio ljudskog postojanja. Stopalo se u tradicionalnoj kineskoj medicini smatra kao drugo srce ljudskih bića, stopalo u biomehaničkom pogledu preuzima i kontrolira značajne i opasne sile udara između tla i ljudskog tijela, glede toga jer stopalo pruža potreban doprinos u balansiranju i stabilnosti mišićno - skeletnog sustava. Problemi sa stopalima su česti, u rasponu od jednostavnih poremećaja, kroz složene bolesti pa sve do patoloških deformacija zglobova [1].

Ljudska stopala, u nazivniku hoda, kao kretanja, u prosjeku života čovjeka, u ekvivalentu, rezultiraju udaljenošću hoda od pet puta oko zemlje, ali im i pored toga ljudi daju manje pažnje nego što zaslužuju i rijetko nose odgovarajuću i najbolju obuću [2]. Čimbenici koji ukazuju na odluku o kupnji kod potrošača su i nadalje antropometrijski oblik kao najvažniji funkcionalni čimbenik udobnosti i zajedno s izgledom i cijenom, jedan je od najznačajnijih elemenata razmatranja za korisnike prilikom kupovine nove obuće [3].

\section{ANATOMIJA STOPALA}

U ergonomijskom i biomehaničkom pogledu funkcionalno zdravo stopalo je skladno usklađen mehanizam koji se sastoji od koštanih elemenata, mišića i tetiva.

Postoje tri dijela koštanog okvira stopala; preplus, plus i prsti. Preplus se sastoji od sedam kratkih spužvastih kostiju, koje su poredane u dva reda. $U$ prvom redu su: vrh, vrh u lateralnom obliku, srednji i medijalni klin kostiju. U stražnjem redu su RAM i peta kostiju. Plus se sastoji od pet kratkih tubularnih kostiju, osnove oblika zglobova s kostima u obliku kocke i klinova, njihove zglobne strukture su povezane sa strukturama kostiju prstiju. Prsti se sastoje od tri elementa: palčani, srednji i glavni. Palac se formira samo iz glavnog i srednjeg elementa, slika 1.

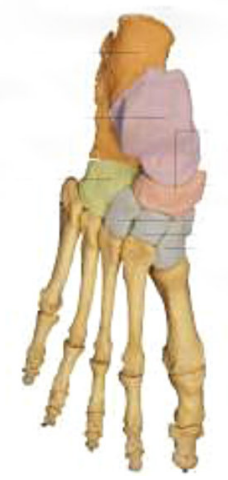

Slika 1. Anatomija stopala

Lukovi stopala su u biomehaničkom pogledu najvažniji strukturni element stopala, koji određuje sve njegove funkcionalne sposobnosti. Zahvaljujući pravilno formiranim lukovima u ranoj mladosti, stopalo obavlja 
niz potrebnih biomehaničkih I automatiziranih funkcija, kao primjerice; distribuciju tijela pri kretanju i podešavanju ravnoteže, ublažavanje udaraca u tlo, odnosno generiranu sposobnost za ublažavanje, akumulaciju otpuštanje energije koja nastaje biomehanizmom hodanja.

Općenito, lukovi stopala rade kao sustav biomehaničke amortizacije, pružajući maksimalnu udobnost pokreta s minimalnim posljedicama za tijelo. Oštećenje ove veze može dovesti do poremećaja cijelog mišićno - skeletnog mehanizma, glede toga, jer je tijelo kompleksna i jedinstvena cjelina, pri čemu se i najmanja promjena u bilo kojem pojedinom dijelu, izravno odražava na cjelokupni sustav. Tako primjerice, ravna stopala mogu uzrokovati oštećenje koljena, zglobova kukova, deformacije kralježnice i poremećaja rada, kao i biološke pozicije unutarnjih organa. Navedeno je rezultat činjenice, da ako stopalo na odgovarajući način ne obavlja svoje funkcije (amortizacija, balans, itd), onda skeletne konstrukcije više razine preuzimaju konstruktivne zadaće funkcija skeletnih elemenata niže razine (koljeno, kuk zglobova, kralježnica). A budući da biološki izvorno nisu prilagođeni ovoj vrsti radnih zadataka i opterećenja, navedeni sustavi su u svakodnevici takvog nepravilnog korištenja mnogo ranjiviji i osjetljiviji.

Uzdužni biomehanički luk stopala nalazi se na unutarnjem rubu stopala, unutar uzdužnog svoda. Vanjski uzdužni luk nastaje mehanikom metatarzalnih kostiju, kuboidom i kostima pete. Uloga vanjskog uzdužnog lučnog svoda je potporna funkcija u statičkim i dinamičkim tjelesnim radnim aktivnostima. Unutarnji uzdužni luk, za razliku od vanjskog luka, izvodi veći broj raznovrsnih biomehaničkih funkcija prigušivanja i elastičnosti, slika 2.

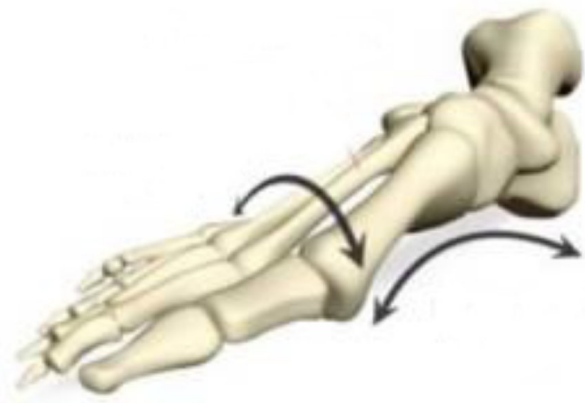

Slika 2. Anatomija vanjskog i unutarnjeg uzdužnog lučnog svoda stopala

Stopalo uobičajeno ima tri segmentalne točke biomehaničke podrške Metatarzalnih kostiju. Kod primjerice, spuštenih (ravnih) stopala, dolazi do antropometrijskih promjena tih segmentalnih točaka. Takve promjene radikalno utječu na promjenu biomehanike hoda i rezultiraju raznovrsnim poremećajima unutar mišićno - skeletnog sustava.

Ovaj specifičan dizajn u obliku svoda, formira se i održava na isti način zahvaljujući raznim ligamentima i mišićima. Ligamenti ostvaruju ulogu pasivnih elemenata, dok mišići djeluju kao aktivni entiteti i ostvaruju jednako vrijednu ulogu u funkcionalnoj strukturi stopala. Postoje tri skupine mišića u stopalu; unutarnji mišići koji su odgovorni za biomehaničko kretanje palca, vanjska skupina mišića za kretanje malog prsta, i središnji mišići koji sudjeluju u stvaranju biomehaničkih pokreta svih prstiju [4]

\section{METODE ODREĐIVANJA DIMENZIJA STOPALA}

Tradicionalna metoda mjerenja, temelji se na određivanju duljine i širine gazišta obuće, mada bi kolokvijalno bilo razumljivije ukoliko bi se te izmjere nazivale: duljina i širina gazišta - stopala. Za razliku od dviju temeljnih dimenzija tradicionalnog određivanja dimenzijskih odnosa stopala unutar postupaka konstrukcije obuće, suvremeni, digitalizirani pristupi, 3D skeniranja stopala, unutar svojih akvizicijskih metoda omogućuju dobivanje daleko većeg broja mjernih pokazatelja, koji nisu samo unutar područja dužinskih vrijednosti, već determiniraju i veći broj trodimenzionalnih individualnih referenci korisnika.

\subsection{Tradicionalna metoda}

Kako bi se što pouzdanije odredila pristalost obuće, potrebno je odrediti koji broj(eve) korisnik nosi, odnosno koja je korisnikova duljina i širina stopala, pri čemu je otegotna okolnost, različitost modela kalupa, različitih proizvođača. širinu stopala, uz napomenu da je stopalo potrebno mjeriti u odgovarajućoj čarapi (tanjoj za ljetnu, odnosno debljoj za zimsku obuću), kao i to da je potrebno izmjeriti oba stopala, glede nejednakosti istih, a unutar daljnjih razmatranja rabiti veću izmjerenu vrijednost.
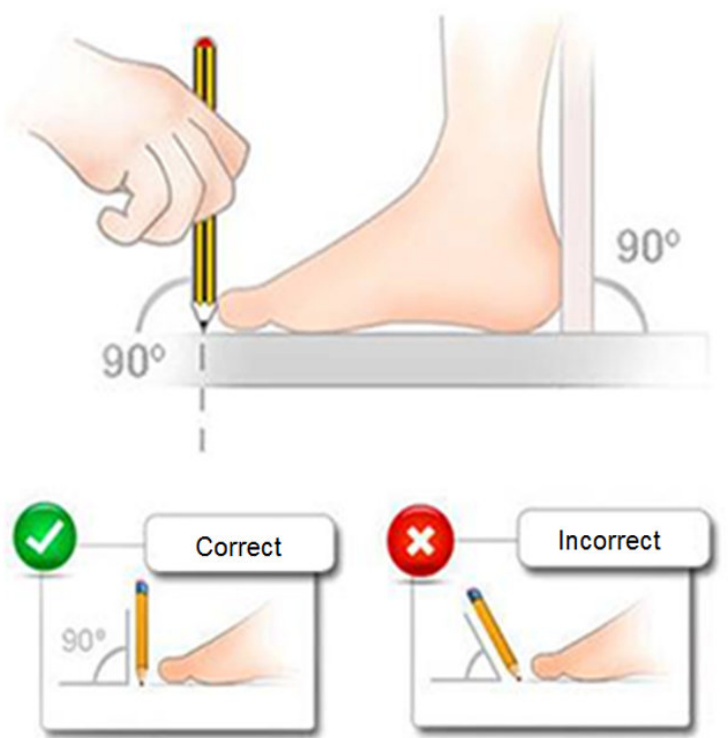

Slika 3. Tradicionalna ručna izmjera gazišta stopala [5]

Prema istom načelu obrisa tlocrtnog traga stopala, izmjeri se i širina na najširem dijelu stopala, kao sekundarna mjera tradicionalnog mjernog postupka.

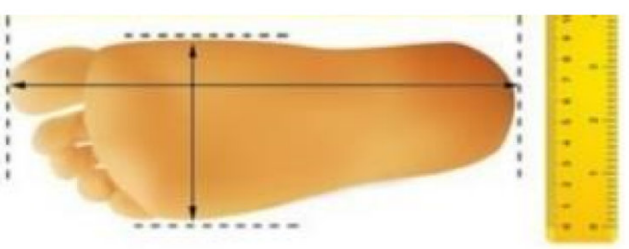

Slika 4. Tradicionalne izmjere duljine i širine gazišta stopala

Mnogi proizvođači uz dimenziju duljine, često označavaju i širinu obuće, načelno za; usko, srednje (normalno) i široko stopalo.

Dužina stopala je samo osnova u određivanju odgovarajuće veličine obuće. Za primjerice duljinu stopala, od $25,5 \mathrm{~cm}$, u principu odgovara veličinski broj 41 , ali zavisno od proizvođača mogu odgovarati i brojevi; 40, 40,5, 402/3, 41, 411/3, 41,5, a nisu rijetki ni slučajevi iz prakse, kada je za primjerice promatranu duljinu stopala, od $25,5 \mathrm{~cm}$, bio odgovarajući i pristajali, i broj 38 ?!

Proizvođači, poglavito brendirane obuće, uglavnom na svojim proizvodima imaju, informativnu etiketu s brojevima u različitim mjernim jedinicama (EUR, UK, US, JPN ...), a često i mjeru izraženu u cm. Japanska mjera (JPN ili JP) je iznimno korisna, glede toga jer je također izražena $u$ $\mathrm{cm}$. Ta mjera, dužina u cm, je najbitnija za pouzdano određivanje, hoće li obuća pristajati, ili ne. Potrebno je da ta mjera bude barem nešto veća od izmjerene duljine stopala, iskustveno za otprilike $0,5 \mathrm{~cm}$ (dužina $\mathrm{u} \mathrm{cm}=$ dužina stopala $+0,5 \mathrm{~cm})$.

Unutar tabele 1 dan je usporedni prikaz; dužine stopala, Mondopoint, kao i brojevi obuće EUR, UK, US, odnosno JP/CN. U recentno vrijeme u opticaju je i tzv. Mondopoint mjerni sistem (u mm), koji zapravo odgovara mjeri u cm i kojim se pokušava standardizirati veličina obuće prema normnom nizu ISO 9407:1991 - "Shoe sizes-Mondopoint system of sizing ..."

Važno je naglasiti da su tradicionalni postupci uzimanja mjera, vezani uz pripadnu tradicionalnu masovnu proizvodnju i prodaju obuće, 
primjenljivi isključivo za uobičajeno - normalno i biometrijski zdravo stopalo

Svakako da postoje i slučajevi koji ne spadaju u ovu kategoriju kao sto su manje ili više usko ili široko stopalo, deblje stopalo u predjelu skočnog zgloba ili stopala s nekim oblikom urođenog ili stečenog deformiteta, kao posljedica gojaznosti ili moguće patoloških oboljenja, a koji vjerojatno zahtijevaju drugačiji suvremeniji i personaliziraniji pristup određivanja odgovarajuće veličine obuće [6]

Tab. 1. Usporedni prikaz; dužine stopala, Mondopoint, kao i brojevi obuće EUR, UK, US, odnosno JP/CN

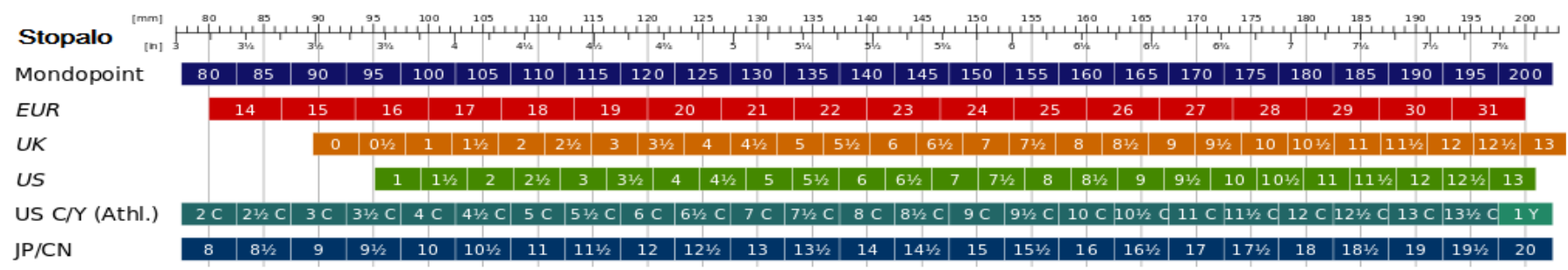

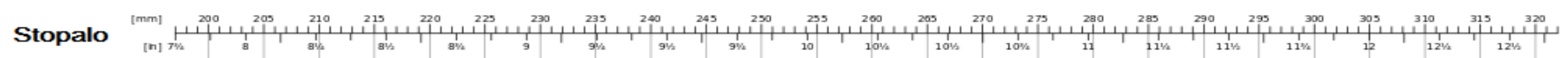

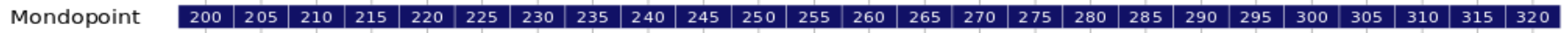

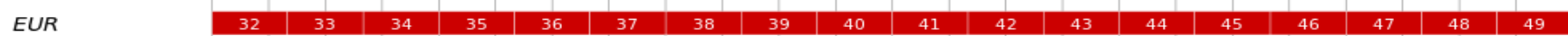

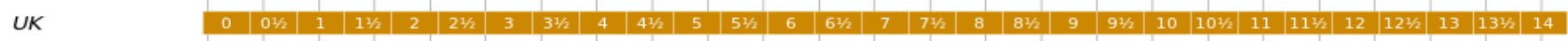

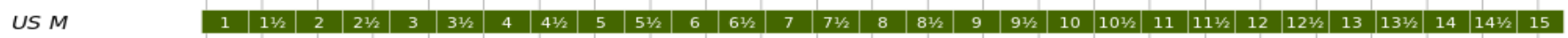

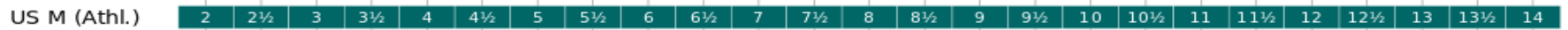

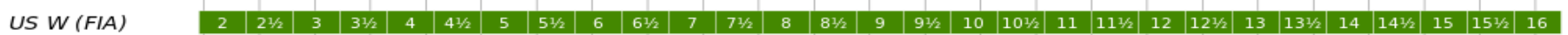

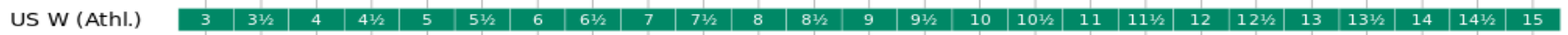

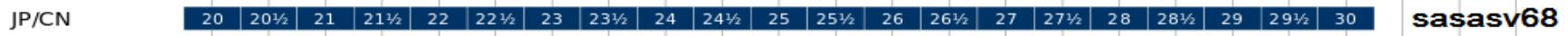

\subsection{Digitalno 3D skeniranje stopala}

3D tehnologija digitalnog skeniranja ostvarila je svoj potencijal u posljednjih nekoliko godina. Koristi se u različitim područjima primjene, poput; medicine, znanosti, inženjerstva, vojne industrije, industrije video igara i sl. [7].

Uporaba 3D tehnologije skeniranja za proizvodnju digitalizirane prezentacije dijelova ljudske anatomije u budućnosti ima potencijal da pomogne promijeniti način na koji je širok spektar proizvoda, sukladno i obuća, dizajniran, konstruiran i izrađen [8].

Postoji mnogo raznovrsnih tehnološki različitih aplikacija 3D skeniranja za potrebe prostorne digitalizacije različitih dijelova ljudskog tijela. Analiza mogućnosti 3D skeniranja za modeliranje stopala, većeg broja istraživanja, pokazala je da su 3D skenovi vrlo pouzdani i znanstveno ponovljivi [9].

Projektiranje obuće kao trodimenzionalnog i prilagođenog, ali često nepersonaliziranog proizvoda, je iznimno složen proces, obzirom na dijametralno oprečne zahtjeve udobnosti i modnih trendova.

Digitalizirane 3D tehnologije, bilo uporabom, 3D

fotogrametrijskih metoda, 3D strukturiranog svjetlosnog skeniranja ili laserskog skeniranja, u konačnici omogućuju, slika 5;

\section{3D skeniranje stopala,}

2. Oblikovanje 3D modela stopala,

3. Pretvaranje u 3D koordinatni točkasti oblak modela stopala,

4. Usporedbu izvedenog 3D digitaliziranog modela stopala s realnim skeniranim stopalom,

5. Dizajn obuće i

6. Različite mogućnosti za proizvodnju prilagođene ili uporabom zahtjevnije obuće.

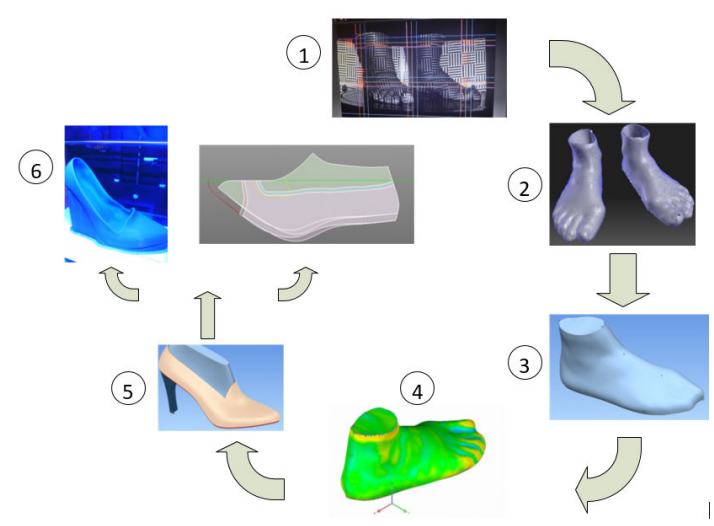

Slika 5. Digitalizirani proces 3D skeniranja stopala, izrade obuće i proizvodnje

$\mathrm{Na}$ slici 6. vizualiziran je proces; postave recentnog mjernog skenogramskog sustava (a), umjeravanja pomoću determiniranih fotogrametrijskih kalibracijskih panela (b, c), skeniranja mjernih entiteta (d, e), u ovom slučaju sustava značajke, mogućnosti skeniranja oba stopala istovremeno i završne virtualizacije izvedenog 3D računalnog prostornog modela snimanja stopala (f) [3].
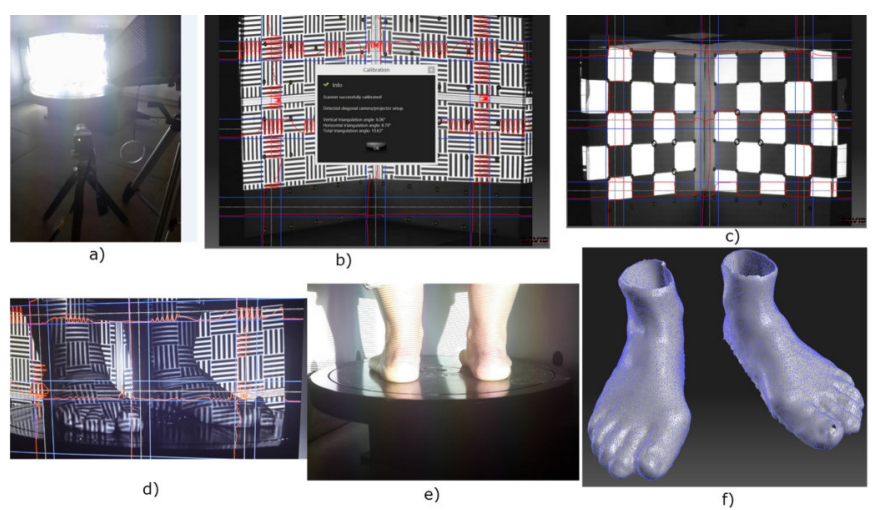

Slika 6. Proces skeniranja; a) Postava, (b, c) Umjeravanje, (d, e) Akvizicija i f) Virtualizacija skenograma 
Kao dio sveobuhvatne dijagnostike, antropometrijskog i bio medicinskog stanja stopala, recentno se primjenjuju, troškovno učinkoviti, vrlo precizni i praktični FootSABA 3D skener stopala, SABALab - a, il primjerice 3D sustav skeniranja razvijen od strane PolyU - a, prikazan na slici 7.

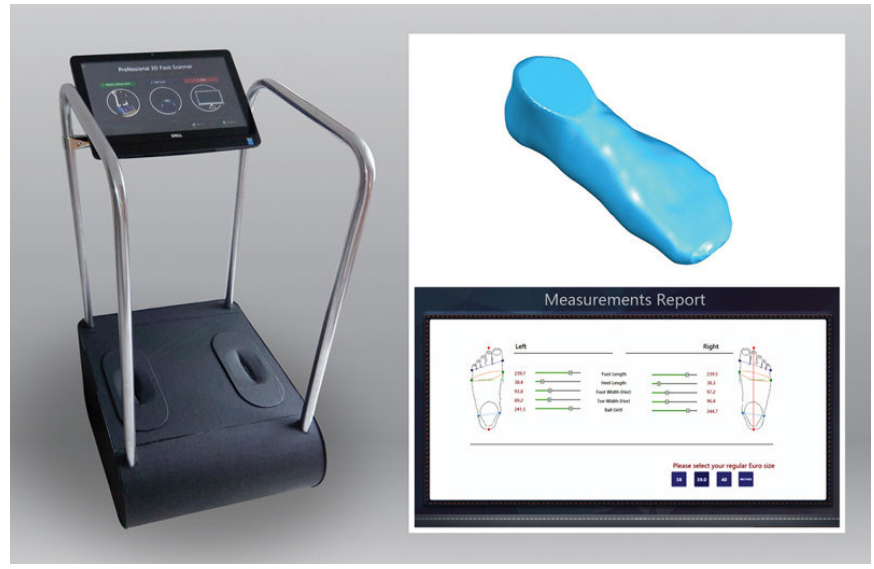

Slika 7. 3D skener stopala s prikazom mjernog i vizualizacijskog zaslona [10]

Unutar reverzibilnih inženjerskih procesa, posebice u procesima 3D skeniranja, uvijek će biti i rezultata nesavršenosti tijekom snimanja podataka. Čak i najnapredniji komercijalni 3D sustavi skeniranja od strane programskih inženjera ulažu iznimne napore, kako bi se sustavima omogućila napredna digitalna 3D analiza prikupljenih podataka, no i pored toga za dubinsku 3D analizu i manipulaciju akviziranih prostornih izmjera podataka često se koriste i dodatni specijalizirani analizatorski računalni programi, primjerice; Geomagic Studio ${ }^{\mathrm{TM}}$ [11].

\section{EKSPERIMENTALNI RAD}

Digitalni 3D Foot Capture and Measurement System "FootSABA" by Sarajko Baksa, namijenjen je prostornom 3D skeniranju stopala u cilju izrade virtualnih 3D modela. Rezultat digitalne antropometrijske izmjere je trodimenzionalni oblak virtualnih koordinatnih točaka, koji predstavlja mjereno tijelo, konkretno na primjerima skeniranih entiteta u redu veličine; 1.387 prostornih poligona, 3.241 prostornih rubnih duljina i 931 prostorno koordinatna verteksa, slika 8.

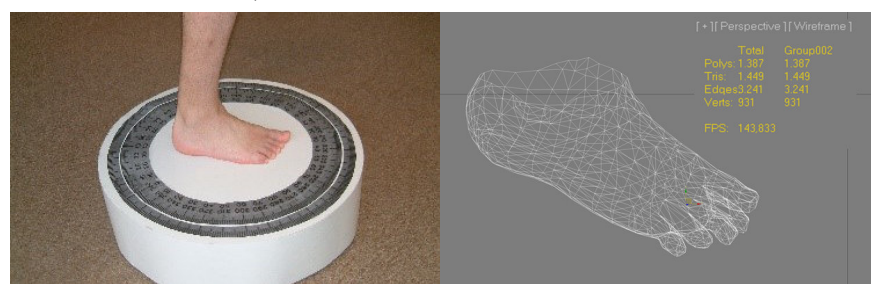

Slika 8. "FootSABA" proces skeniranja i virtualizacijske analize 3D skeniranog modela

Tradicionalna ručna metoda mjerenja provedena je metodama koje su opće prihvaćene i koje se uobičajeno i svakodnevno strukovno primjenjuju prilikom određivanja dimenzija stopala, a sukladno uputama prikazanim na slici 3 i 4 . Mjerenje je provedeno antropometrijskim mjernim alatima utvrđivanja ravninskih dimenzija (antropometrijsko pomično mjerilo, nje. Schublehre).

U oba mjerenja izmjere su provedene na oba stopala, a kako se radilo prvenstveno o antropometrijskim izmjerama, kako bi rezultati bili što signifikantniji, ista su provedena na "bosim" stopalima.

Unutar tabele 2 dani su sumarni rezultati 30 mjernih entiteta, u dimenzijama duljine i širine stopala, za tradicionalnu ručnu i recentnu $3 \mathrm{D}$ digitaliziranu metodu računalne izmjere.
Tab. 2. Tabelarni prikaz sumarnih rezultata mjerenja

\begin{tabular}{|c|c|c|c|}
\hline \multirow[b]{2}{*}{$\begin{array}{l}\text { Anthropometric } \\
\text { measurement }\end{array}$} & \multirow[b]{2}{*}{$\begin{array}{c}\text { Anthropometric } \\
\text { entity }\end{array}$} & \multicolumn{2}{|c|}{ Measurement } \\
\hline & & $\begin{array}{l}\text { Traditional } \\
\text { manual } \\
\text { method }\end{array}$ & $\begin{array}{l}\text { Recent 3D } \\
\text { computer } \\
\text { measurement }\end{array}$ \\
\hline \multirow{2}{*}{ Foot length $(\mathrm{cm})$} & Left foot & 26.71 & 26.69 \\
\hline & Right foot & 26.64 & 26.61 \\
\hline \multirow{2}{*}{ Foot width (cm) } & Left foot & 10.35 & 10.31 \\
\hline & Right foot & 10.25 & 10.27 \\
\hline
\end{tabular}

\section{RASPRAVA I ZAKLJUČCI}

Utvrđena je i opće poznata činjenica da postoji značajna razlika u podacima na prišivenoj deklaraciji (etiketi) koja se nalazi na obući i realnom - izmjerenom stanju veličine obuće.

Preporuka je da se pri kupovini obuće tradicionalnom metodom dužinskog mjernog sustava, primjerice; mjerne vrpce, izmjeri dužina i širina oba stopala, te da se u kupovinu krene s dimenzijama koje su izmjerene na većem stopalu, obzirom da su stopala načelno različitih antropometrijskih veličina. Također, glede dodatne pristalosti obuće, kao značajka udobnosti, preporuka je izvršiti i izmjeru duljine unutarnjeg gazišta kao i duljinu (izvađenog) uloška obuće, obzirom da su i to elementi koji u značajnoj mjeri doprinose udobnosti i pristalosti obuće.

I pored primjene svega navedenog, to ne mora značiti da će obuća biti odgovarajuća i pristajala, glede antropoloških različitosti, ne samo u duljini među stopalima, već i širini, kao i signifikantnim prostornim dimenzijskim razlikama pojedinih segmentalnih presjeka. Tako se primjerice u praksi često događa da ljudi i s medicinskog gledišta zdravim stopalima, teško ili nikako ne pronalaze odgovarajuću i pristalu obuću, glede toga jer im primjerice, po duljini gazišta lijevog stopala odgovara broj; 42, a po duljini desnog gazišta, broj; 43, odnosno, da im po duljini gazišta odgovara broj; 43, a po širini tog istog stopala, broj; 44.

S obzirom na ujednačeni skup mjernih entiteta na kojem se provelo istraživanje unutar ovog rada i stručnosti osobe koja je provodila mjerenje, rasipanje rezultata je razmjerno malo, no i pored toga, jasno je uočljiva razlika između antropometrijskih izmjera lijevog i desnog stopala, kao i preciznosti 3D sustava.

Glede razvoja sustava automatiziranog i digitalnog prostornog uzimanja 3D otiska stopala, više nema potrebe za odabirom dijametralno suprotnih odlika; između dobrog modnog izgleda i ergonomski pristale i antropometrijski individualizirane i odgovarajuće obuće, sada je moguće, korištenjem recentnih $3 \mathrm{D}$ antropometrijskih skenera (primjerice; FootSABA) imati oboje.

S obzirom na iznimno veliki broj prostornih antropometrijskih točaka koje su rezultat 3D izmjere, primjerice; samo u domeni ravninskih izmjera, više od 3.000 prostornih preciznih podataka rubnih duljina, naspram dvije tradicionalno rezultirajuće, 3D FootSABA antropometrijski skener stopala, ostvaruje povećanje u rezoluciji analize i modeliranja od nevjerojatnih $150.000 \%$ i to samo unutar područja ravninskih izmjera.

\section{LITERATURA}

[1] B. Nácher, S. Alemany, J. González, E. Alcántara, J. García Hernández, S. Heras and A. Juan; "A Footwear FitClassification Model Based on Anthropometric data,"

[2] T. S. o. C. a. Podiatrists; "Footwear: A guide to choosing the best shoes for your feet".

[3] E. Piperi, L. M. Galantucci, J. Kacani, E. Shehi, T. Spahiu; "From 3D foot scans to footwear designing \& production“, 6th International Conference of Textile, 20, November 2014, Tirana, Albania

[4] https://rossiyanka-sanatoriy.ru/906-ploskostopie-plantografija (downloads; 20 July 2019) 
[5] https://www.saptac.hr/kako-se-izmjeriti(downloads; 07 July 2019)

[6] http://cafe.limundo.com/thread-276.html

[7] R. Nibedita, K. Asimananda, Z. Yi Fan and L. Ameersing, "3D Foot Scan to Custom Shoe Last," vol. 1, 2010.

[8] S. Telfer and J. Woodburn, "The use of 3D surface scanning for the measurement and assessment of the humanfoot", JOURNAL OF FOOT AND ANKLE RESEARCH, p. 9, 2010

[9] D. Besliu, "Measurement Devices for Custom Shoe Manufacturing, 2011

[10] www.polyu.edu.hk/cpa/milestones/en/201506/knowledgetransfer/3d scanner creates a whole new footwear experie/index.html (14 July 2019)

[11] 3DSystems, http://www.geomagic.com/en/products/studio (downloads; 12 July 2019)

\section{Acknowledgements}

This paper describes the results of research being carried out within the project "Centar održivog razvoja"/"Center of sustainable development", cofinanced by the European regional development fund and implemented within Operational Programme Competitiveness and Cohesion 2014 - 2020, based on the call "Investing in Organizational Reform and Infrastructure in the Research, Development and Innovation Sector". 